\title{
Self-Powered Bipolar Gate-Driver Power Supply Circuit for Neutral-Point-Clamped Converters
}

\author{
S. Busquets-Monge, A. Filbà-Martínez, J. Nicolás-Apruzzese, and J. Bordonau \\ Department of Electronic Engineering \\ Universitat Politècnica de Catalunya \\ Barcelona, Spain \\ sergio.busquets@upc.edu
}

\begin{abstract}
The design of gate-driver power supply (GDPS) circuits for multilevel neutral-point-clamped converters is a challenge due to the large number of power switches required and the fact that each device presents a different GDPS reference node. This paper presents a compact self-powered bipolar GDPS circuit, consisting of two subcircuits connected across the power switches, which altogether produce all the positive and negative supply voltages required by the GDs. As these subcircuits essentially contain semiconductor components, they can be integrated with the power switch and gate driver, to produce a compact cell from which obtain a compact converter leg implementation. Overall, this BGDPS design is suitable for all types of NPC multilevel topologies with any type of power transistor, although it is most suitable for moderate device voltage ratings. The good performance of the proposed BGDPS circuit has been confirmed through experiments on a conventional two-level leg, and on three-level and four-level active-clamped converter legs.
\end{abstract}

Keywords-gate-driver power supply; multilevel; neutral point clamped, self-powered.

\section{INTRODUCTION}

The interest in multilevel conversion techniques has been steadily increasing over the last two decades. A number of multilevel converters are already available as commercial products for several applications and it is still a hot research topic [1]. Their advantage is clear in high-power high-voltage applications, but they can also provide benefits at medium or low power and voltage levels. In general, multilevel conversion features improved efficiency, lower harmonic distortion, and lower common mode voltage, compared to conventional twolevel conversion.

Among the different multilevel converter topologies, the most popular and widely used is the three-level neutral-pointclamped (NPC) [2]. An $n$-level neutral-point-clamped leg is functionally equivalent to a single-pole $n$-throw switch. The leg ac terminal can be connected to any of the $n$ available dc-link points through an arrangement of only power semiconductor devices. The dc-link points are typically generated through a series connection of capacitors. The topology can be regarded as an extension of the two-level half-bridge topology of Fig. 1. Fig. 2 and Fig. 3 show this extension in the case of the passiveclamped (or diode-clamped) and active-clamped (transistorclamped) versions of the NPC family, assuming that all devices have the same voltage rating, corresponding to a blocking voltage of $v_{\mathrm{dc}} /(n-1)$. Although the operation of NPC converters with more than three-levels was initially deemed unfeasible at a wide range of operating conditions, due to the dc-link capacitor voltage balancing problem, several modulation and control techniques are already available today to solve this issue [3]. NPC topologies have a potential for a very compact implementation, because the leg does not require energy storage elements such as capacitors or inductors. However, they require a large number of power switches, especially as the number of levels increases. In addition, each power switch requires ancillary circuitry: basically, a gate driver (GD) and a gate-driver power supply (GDPS). Incorporating a GDPS for each power switch is especially challenging, as the reference node for each switch is in general different.

There are several options to generate the regulated and isolated low voltages necessary to feed each GD. For instance, one can use a set of low-power dc-dc converters with galvanic isolation, bootstrap charge pump circuits, resonant circuits [4], etc. However, these circuits present important drawbacks such as incorporating bulky components (i.e., inductors or transformers), being difficult to integrate, causing electromagnetic interference problems, or being asymmetric from both a topological and operation point of view. Instead, the unipolar GDPS circuit connected across the switch power terminals shown in Fig. 4 and proposed in [5]-[8] offers a very interesting solution for multilevel converters, since the circuit can be monolithically integrated within the power switch, and therefore represents a modular, symmetric, and compact solution. Reference [9] has already demonstrated the operation of this GDPS circuit in a three-level diode-clamped topology. Design guidelines to optimize the performance of this GDPS circuit have been discussed in [10].

The operation of the GDPS circuit presented in Fig. 4 is summarized as follows. Switch $\mathrm{S}_{\mathrm{m}}$ represents the main power switch, whose gate driver is to be fed. Capacitor $C_{\mathrm{s}}$ stores the

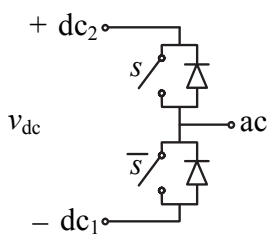

Fig. 1. Two-level half-bridge leg topology. 


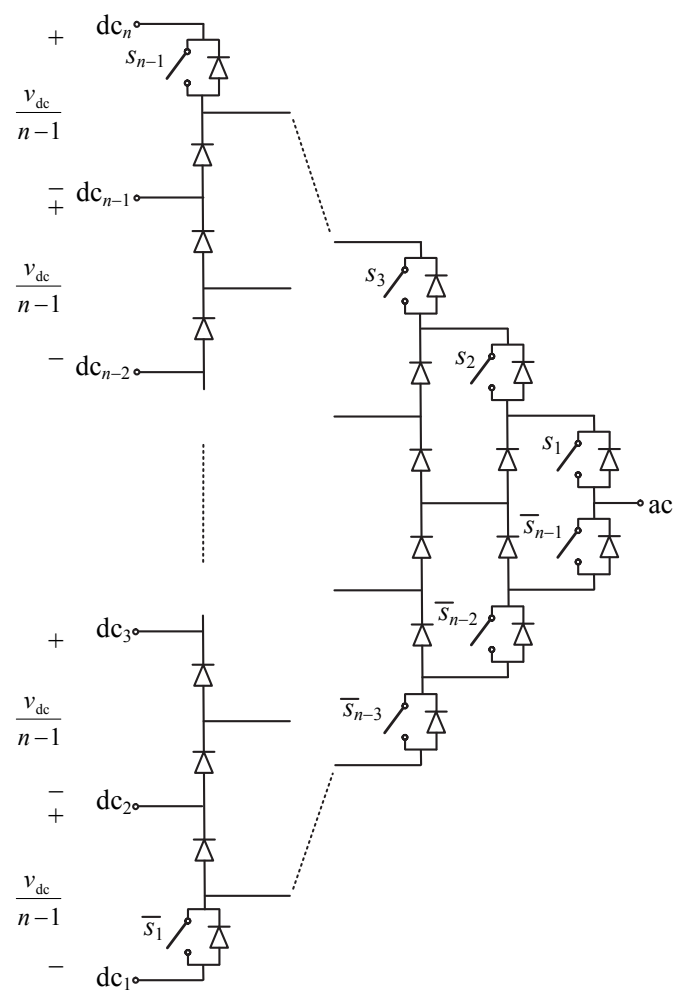

Fig. 2. Multilevel passive-clamped (diode-clamped) NPC topology.

energy necessary to feed this gate driver. Voltage $v_{\mathrm{cc}}$ is the generated positive GDPS voltage with reference to the source of $\mathrm{S}_{\mathrm{m}}$. During the $\mathrm{S}_{\mathrm{m}}$ turn-off transient with $i_{\mathrm{m}}>0$, part of the current initially flowing through $\mathrm{S}_{\mathrm{m}}$ flows through the auxiliary switch $S_{a}$ charging capacitor $C_{s}$. The zener diode $D_{z}$, polarized by diode $\mathrm{D}_{\mathrm{p}}$, limits the value of $v_{\mathrm{cc}}$ and the blocking diode $\mathrm{D}_{\mathrm{b}}$ prevents the discharging of $\mathrm{C}_{\mathrm{s}}$ when $\mathrm{S}_{\mathrm{m}}$ is on. $\mathrm{S}_{\mathrm{m}}$ and $\mathrm{S}_{\mathrm{a}}$ typically share the resulting turn-off loss. Overall, the energy to recharge $C_{s}$ is obtained from energy that would otherwise be lost during the turn-off transition; i.e., part of $\mathrm{S}_{\mathrm{m}}$ turn-off loss is recycled to power the GD. If $i_{\mathrm{m}}<0$, the energy to recharge $\mathrm{C}_{\mathrm{s}}$ is obtained from the dc voltage source connected across the switch during its off state, with lower conversion efficiency. In a discrete implementation of the GDPS circuit, it is convenient to replace $D_{p}$ by a resistor $R_{p}$ to better control the polarizing current through $\mathrm{D}_{\mathrm{z}}$.

The self-powered GDPS circuit in Fig. 4 generates a single positive voltage $v_{\mathrm{cc}}$ to power the gate driver. However, many power switches (insulated-gate bipolar transistors or fieldeffect transistors) require a bipolar GDPS to guarantee a safe turn-off transition. Aiming to provide a simple solution for these cases, this paper proposes an extension of the GDPS circuit in Fig. 4 to provide both a positive and a negative GDPS voltage for each switch.

The paper is organized as follows. Section II presents the proposed topology and its operating principle. Section III proves the good performance of the proposed circuit through experiments on several legs with different number of levels. Finally, Section IV outlines the conclusions.

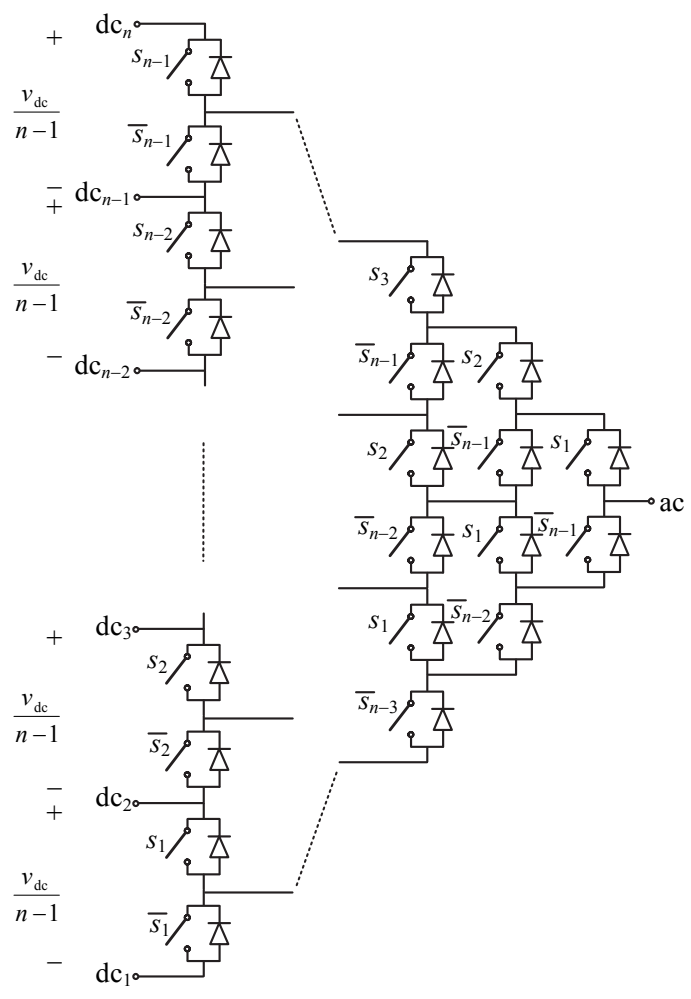

Fig. 3. Multilevel active-clamped (transistor-clamped) NPC topology.

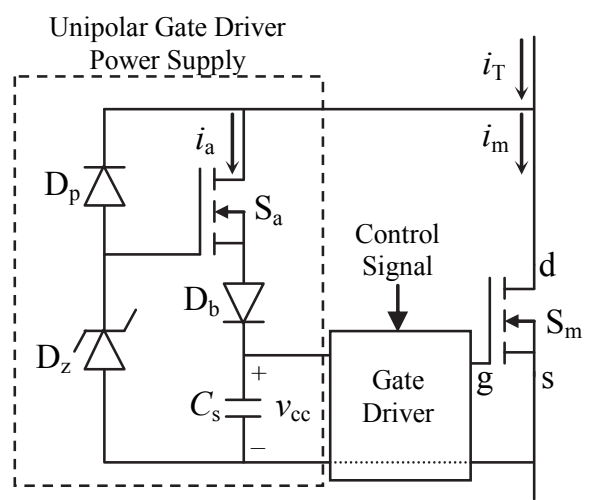

Fig. 4. Self-powered unipolar gate-driver power supply circuit.

\section{Bipolar GATE-Driver POWER-Supply TOPOLOGY AND OPERATION PRINCIPLE}

\section{A. Topology}

Fig. 5 presents the proposed topology to generate both positive and negative supply voltages to feed the gate driver of the main switch $\mathrm{S}_{\mathrm{m}}$. The GDPS combines two subcircuits: GDPS + in charge of generating the positive supply voltage $v_{\mathrm{cc}}^{+}$ and GDPS- in charge of generating the negative supply voltage $v_{\text {cc }}^{-}$. Subcircuit GDPS + is the original unipolar GDPS circuit depicted in Fig. 4. Subcircuit GDPS- represents a symmetrical extension, incorporating the same components as in GDPS+, except for their parameter values. In addition, 


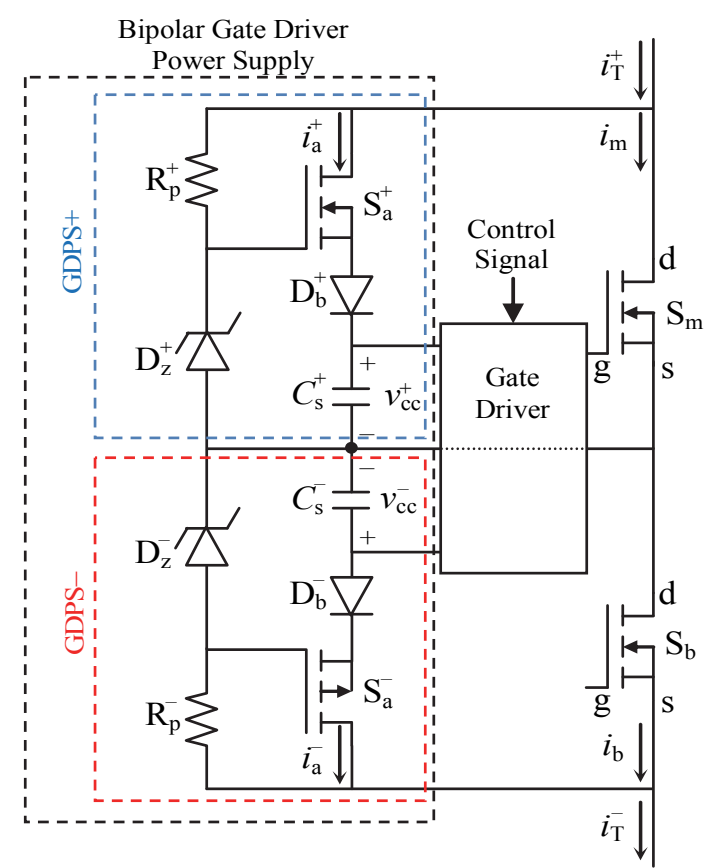

Fig. 5. Proposed self-powered bipolar gate-driver power supply circuit.

transistor $\mathrm{S}_{\mathrm{a}}^{-}$is a p-channel metal-oxide-semiconductor fieldeffect transistor (MOSFET) while $\mathrm{S}^{+}{ }_{\mathrm{a}}$ is an $\mathrm{n}$-channel MOSFET. Subcircuit GDPS- must be connected across a bottom power switch $S_{b}$, whose drain is connected to the source of the main power switch $\mathrm{S}_{\mathrm{m}}$.

\section{B. Operation Principle}

The operating principle of GDPS + has already been explained in Section I. The operating principle of GDPS- is analogous. Capacitor $\mathrm{C}^{-}$s stores the energy necessary to feed the $\mathrm{S}_{\mathrm{m}}$ gate driver through the negative power supply. Voltage $v_{c c}^{-}$is the generated negative GDPS voltage with reference to the source of $\mathrm{S}_{\mathrm{m}}$. During the turn-off process of $\mathrm{S}_{\mathrm{b}}$ with $i_{\mathrm{b}}>0$, part of the current initially flowing through $\mathrm{S}_{\mathrm{b}}$ flows through the auxiliary switch $\mathrm{S}_{\mathrm{a}}^{-}$charging capacitor $\mathrm{C}_{\mathrm{s}}^{-}$. The zener diode $\mathrm{D}_{\mathrm{z}}^{-}$, polarized by resistor $\mathrm{R}_{\mathrm{p}}^{-}$, limits the value of $v_{\mathrm{Cs}}^{-}$and the blocking diode $\mathrm{D}_{\mathrm{b}}^{-}$prevents the discharging of $\mathrm{C}_{\mathrm{s}}^{-}$when $\mathrm{S}_{\mathrm{b}}$ is on. $\mathrm{S}_{\mathrm{b}}$ and $\mathrm{S}_{\mathrm{a}}^{-}$typically share the resulting turn-off loss. Overall, the energy to recharge $\mathrm{C}_{\mathrm{s}}^{-}$is obtained from energy that would otherwise be lost during the turn-off transition of $\mathrm{S}_{\mathrm{b}}$; i.e., part of $\mathrm{S}_{\mathrm{b}}$ turn-off loss is recycled to power the GD. If $i_{\mathrm{b}}<0$, the energy to recharge $\mathrm{C}_{\mathrm{s}}^{-}$is obtained from the dc voltage source connected across $\mathrm{S}_{\mathrm{b}}$ during its off state, with lower conversion efficiency.

\section{EXPERIMENTAL RESULTS}

Experimental tests have been conducted to verify the good performance of the proposed bipolar GDPS circuit for NPC converters. A cell composed of a power MOSFET IRFR4510 $(100 \mathrm{~V}, 56 \mathrm{~A})$ and ancillary circuitry (HCPL-316J GD and the proposed bipolar GDPS) has been designed, as a building block to implement converter legs with any number of levels. The selected components for the bipolar GDPS are listed in Table I. Two diodes in series are used to implement $\mathrm{D}_{\mathrm{b}}$ in GDPS + to fine tune the resulting value of $v^{+}$cc. Fig. 6 shows a picture of the $30 \mathrm{~mm} \times 35 \mathrm{~mm}$ cell, implemented on a printed circuit board.

The cell has then been used to implement three different converter legs: a conventional two-level leg (Fig. 7(a)), a threelevel active-clamped leg (Fig. 7(b)), and a four-level activeclamped leg (Fig. 7(c)). The GDPS- of each power switch is connected across the power switch right underneath. In cases where two $S_{b}$ switches are possible, the one right below in the same column is selected. For instance, in Fig. 7(c), when considering the connection of $\mathrm{S}_{61}$ GDPS-, there are two $\mathrm{S}_{\mathrm{b}}$ candidates $\left(\mathrm{S}_{51}\right.$ and $\left.\mathrm{S}_{52}\right)$ and $\mathrm{S}_{51}$ is selected since it belongs to the same column as $\mathrm{S}_{61}$. All power switches present at least one $\mathrm{S}_{\mathrm{b}}$ candidate except for $\mathrm{S}_{11}$. To solve this issue, the negative supply voltage of $S_{11}$ has been obtained from an external dc power supply.

The resulting three converter legs have been tested under the experimental test configuration depicted in Fig. 8. A constant dc voltage $V=50 \mathrm{~V}$ has been forced across nearby dclink points using independent dc power supplies. The leg is then operated to produce a $10 \mathrm{kHz}$ staircase voltage waveform at the leg ac terminal with equal duty ratios for the connection to all dc-link points. The ac-terminal voltage is applied to a series resistive-inductive load with $L=8.7 \mathrm{mH}$ to produce a fairly constant ac-terminal current $i_{\text {ac }}$. The two configurations illustrated in Fig. 8 allow reaching positive and negative $i_{\mathrm{ac}}$ values and the load resistance is adjusted to operate with an absolute value of $i_{\text {ac }}$ equal to $5 \mathrm{~A}$.

Fig. 9 presents the results of the two-level leg test. All GD supply voltages, switch gate voltages, and the resulting leg ac terminal voltage and current are shown on several synchronized scope captures. Refer to Fig. 7 for the switch nomenclature. All positive and negative supply voltages remain stable at the intended dc value with small ripple. The generated gate voltages of both switches commutate complementarily and

TABLE I

BIPOLAR GDPS COMPONENTS

\begin{tabular}{ccc}
\hline \hline \multirow{2}{*}{ Component } & GDPS + & GDPS- \\
\hline $\mathrm{S}_{\mathrm{a}}$ & IRF5802(150 V,0.9 A) & IRF6217 (-150 V, -0.7 A) \\
$\mathrm{D}_{\mathrm{z}}$ & DDZ9708 $(22 \mathrm{~V} @ 50 \mu \mathrm{A})$ & DDZ9697 $(10 \mathrm{~V} @ 50 \mu \mathrm{A})$ \\
$\mathrm{D}_{\mathrm{b}}$ & $2 \times M B R A 140(40 \mathrm{~V}, 1 \mathrm{~A})$ & $\mathrm{MBRA} 140(40 \mathrm{~V}, 1 \mathrm{~A})$ \\
$R_{\mathrm{p}}$ & $56 \mathrm{k} \Omega$ & $56 \mathrm{k} \Omega$ \\
$\mathrm{C}_{\mathrm{s}}$ & $330 \mathrm{nF}$ & $330 \mathrm{nF}$ \\
\hline \hline
\end{tabular}

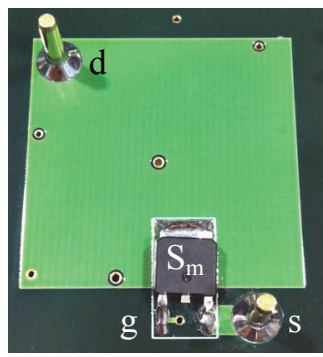

(a)

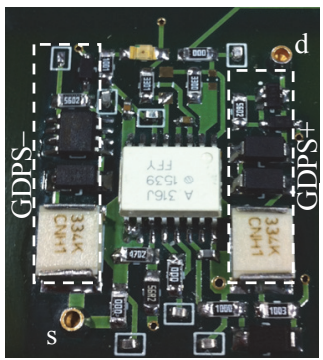

(b)
Fig. 6. Implementation of the bipolar GDPS for each switch of the experimental prototypes. (a) Main power switch on one side of the printed circuit board. (b) Gate driver circuitry and bipolar GDPS on the other side. 


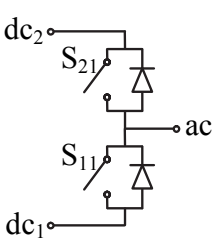

(a)

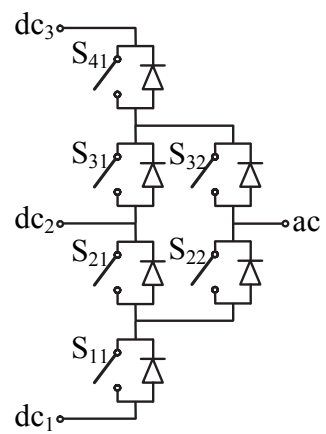

(b)

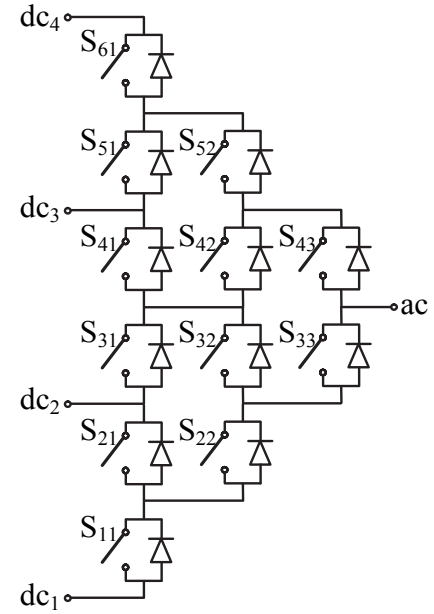

(c)

Fig. 7. Switch nomenclature for the implemented legs. (a) Two-level leg. (b) Three-level active-clamped leg. (c) Four-level active-clamped leg.

with an adequate blanking time between a positive and a negative voltage value in the same manner as would have been occurred with an external GDPS. The resulting ac-terminal voltage presents two levels and the ac-terminal current is fairly constant.

Fig. 10 presents the results of the three-level leg test. All scope captures are again synchronized. All GD supply voltages are regulated at proper voltage values, and the leg generates the expected three-level ac terminal voltage. The spikes appearing in the waveforms are noise captured by the used differential probes.

Fig. 11 presents the results of the four-level leg test. The GD supply voltage waveforms are not displayed for the sake of brevity, but their values can be indirectly observed through the twelve captured switch gate voltages. Again, the leg operates properly to generate the expected four-level ac-terminal voltage.

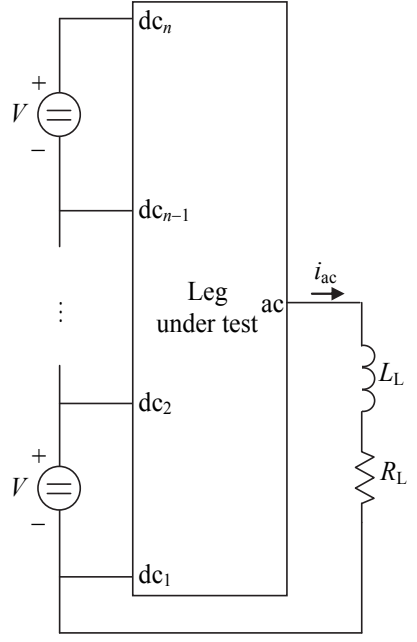

(a)

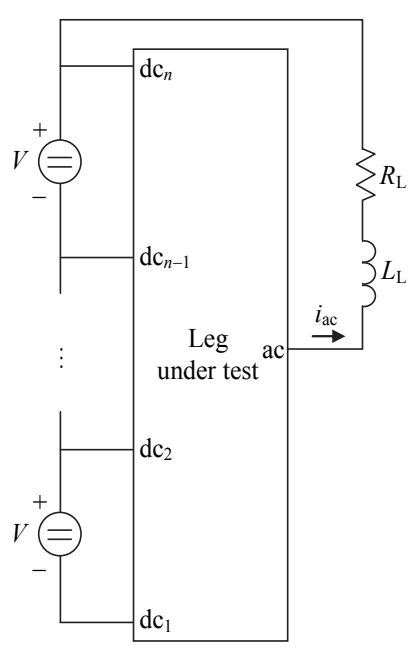

(b)
Fig. 8. Experimental test configuration. (a) For positive $i_{\mathrm{ac}}$. (b) For negative $i_{\mathrm{ac}}$.

\section{CONCLUSION}

This paper has presented a self-powered bipolar GDPS circuit, consisting of two subcircuits (GDPS+ and GDPS-) connected across the power switches. The proposed bipolar GDPS generates the regulated positive and negative supply voltages necessary to drive the power switch. The energy is partly obtained from recycling switching losses in the power switches. As these subcircuits essentially contain semiconductor components, they can be monolithically integrated within the power switch, with the exception of the power supply capacitors $\mathrm{C}_{\mathrm{s}}$. One GDPS+ circuit and one GDPS- circuit can be integrated with any type of power switch and a GD in order to produce a compact cell from which NPC converter legs with any number of levels can be easily built interconnecting several of these cells. The performance is satisfactory, although a single external dc power supply is necessary for the negative supply voltage of the leg bottom switch. The proposed bipolar GDPS circuit is most suitable for moderate power-switch voltage ratings.

\section{ACKNOWLEDGMENT}

This work has been supported by the Ministerio de Economía, Industria y Competitividad, Spain, under Grant DPI2017-89153-P (AEI/FEDER, UE).

\section{REFERENCES}

[1] H. Akagi, "Multilevel converters: fundamental circuits and systems," Proc. IEEE, vol. 105, pp. 2048-2065, Nov. 2017.

[2] J. Rodriguez, S. Bernet, P. Steimer, and I. Lizama, “A survey on neutral point clamped inverters,” IEEE Trans. Ind. Electron., vol. 57, pp. 22192230, July 2010.

[3] S. Busquets-Monge, A. Filbà-Martínez, S. Alepuz, and A. Calle-Prado, "A modulation strategy to operate multilevel multiphase diode-clamped and active-clamped dc-ac converters at low frequency modulation indices with dc-link capacitor voltage balance," IEEE Trans. Power Electron., vol. 32, pp. 7521-7533, Oct. 2017.

[4] H. Wang and F. Wang, "A self-powered resonant gate driver for highpower MOSFET modules", in Proc. IEEE Applied Power Electronics Conference, 2006, pp. 183-188. 


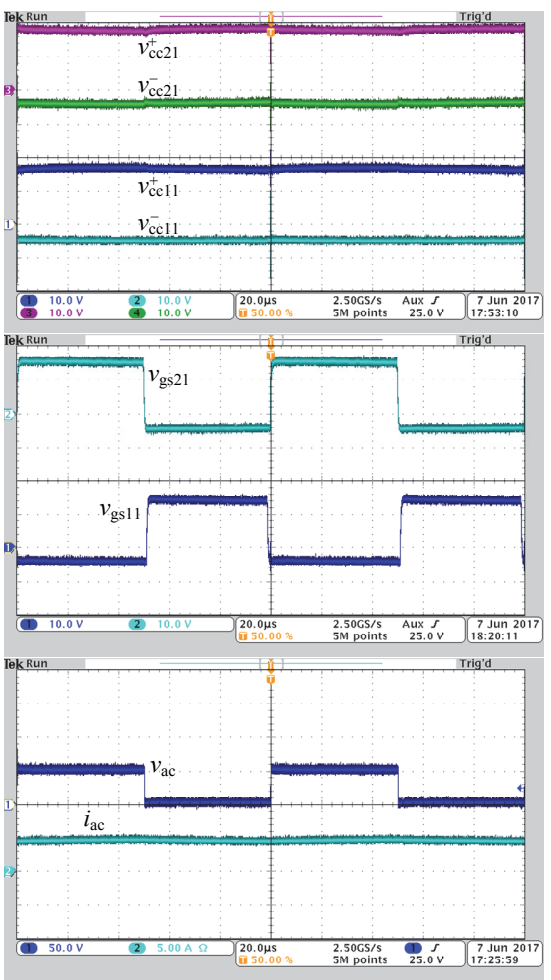

(a)
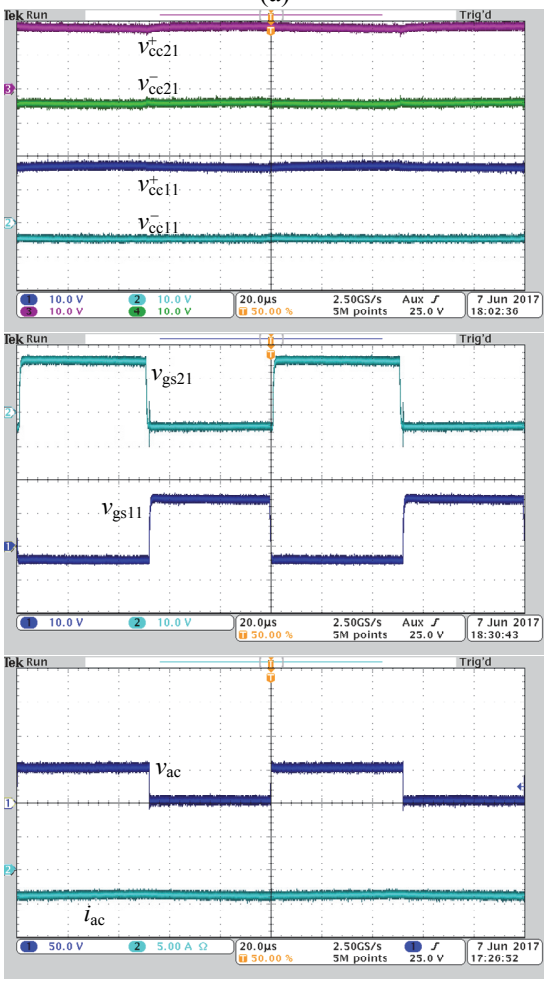

(b)

Fig. 9. Experimental results for a two-level leg. (a) $i_{\mathrm{ac}}>0$. (b) $i_{\mathrm{ac}}<0$.

[5] R. Mitova, J.-C. Crebier, L. Aubard, and C. Schaeffer, "Fully integrated gate drive supply around power switches," IEEE Trans. Power Electron., vol. 20, pp. 650-659, May 2005.

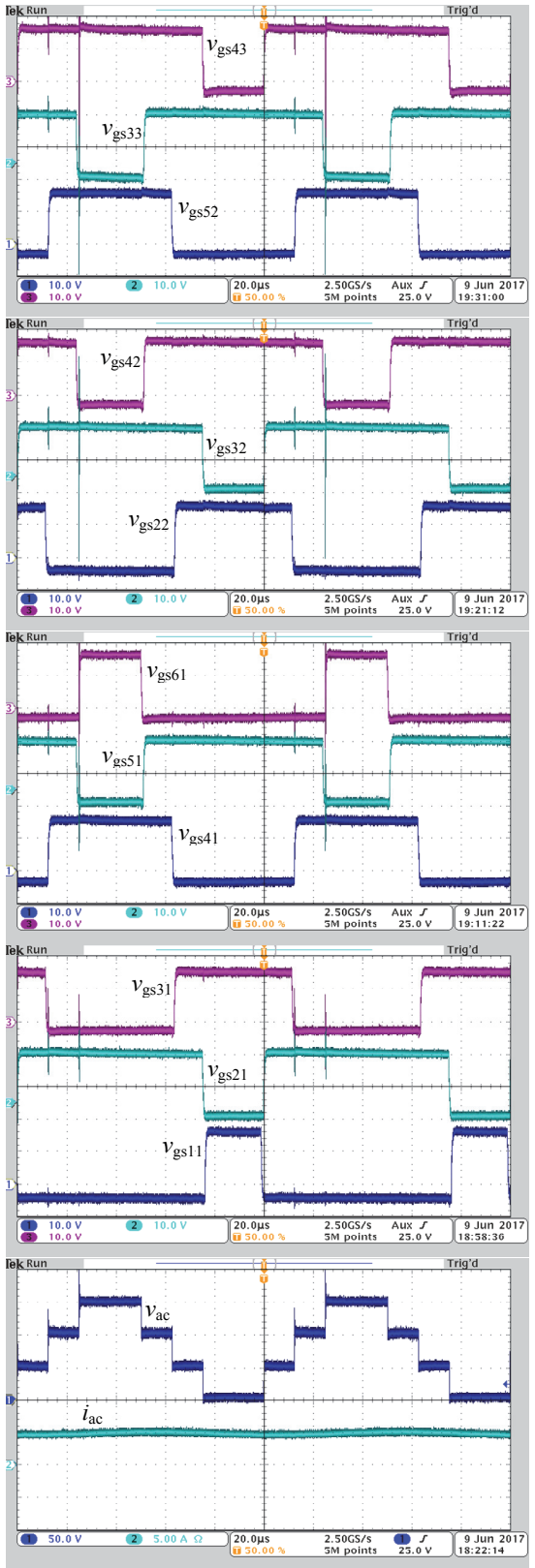

(a)

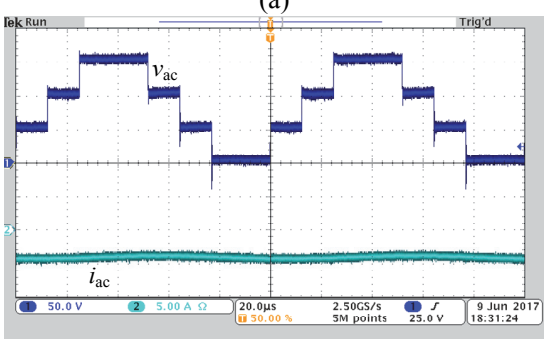

(b)

Fig. 11. Experimental results for a four-level active-clamped leg. (a) $i_{\mathrm{ac}}>0$. (b) $i_{\text {ac }}<0$.

[6] J.-C. Crebier and N. Rouger, "Loss free gate driver unipolar power supply for high side power transistors," IEEE Trans. Power Electron., vol. 23, pp. 1565-1573, May 2008. 


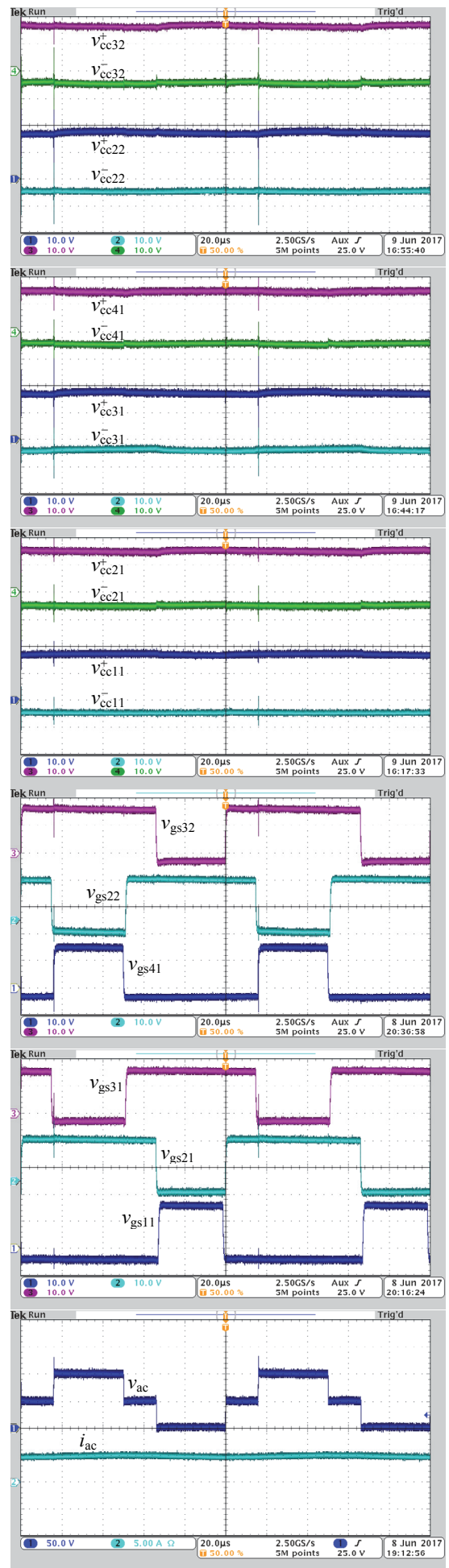

(a)

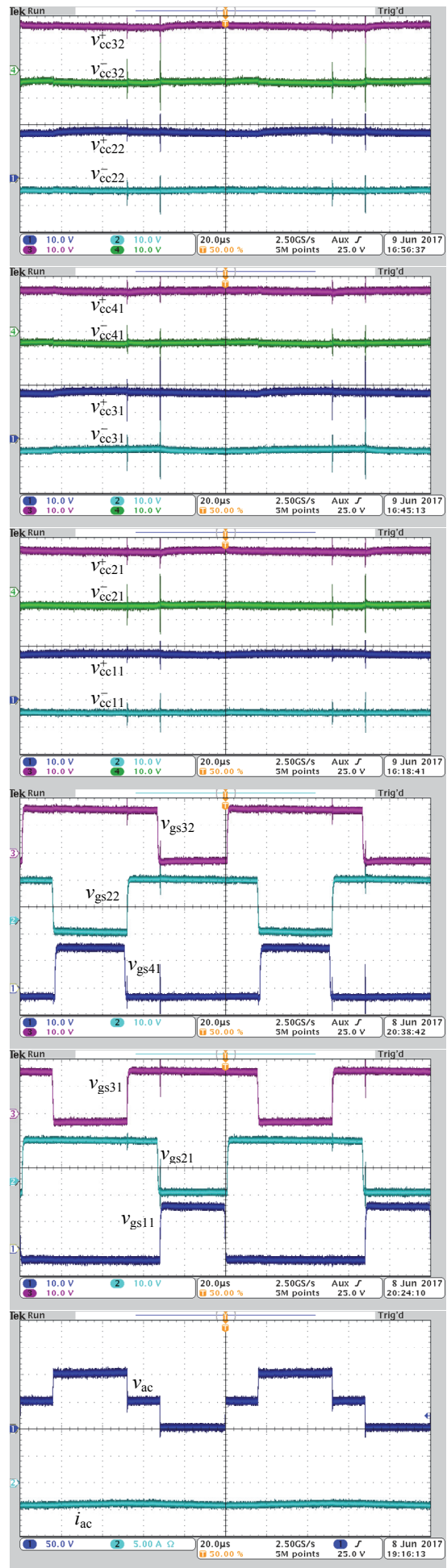

(b)

Fig. 10. Experimental results for a three-level active-clamped leg. (a) $i_{\mathrm{ac}}>0$. (b) $i_{\mathrm{ac}}<0$.

[7] N. Rouger and J.-C. Crebier, "Toward generic fully integrated gate driver power supplies," IEEE Trans. Power Electron., vol. 23, pp. 2106-2114, July 2008.

[8] N. Rouger, J.-C. Crebier, H. Tran Manh, and C. Schaeffer, "Toward integrated gate driver supplies : Practical and analytical studies of high-voltage capabilities," in Proc. IEEE Power Electronics Specialists Conf., 2008, pp. 873-879.
[9] S. Busquets-Monge, J. Rocabert, J.-C. Crebier, and J. Peracaula, "Diode-clamped multilevel converters with integrable gate-driver power-supply circuits," in Proc. European Conference on Power Electronics and Applications, 2009, pp. 1-10.

[10] S. Busquets-Monge, D. Boroyevich, R. Burgos, and Z. Chen, "Performance analysis and design optimization of a self-powered gate-driver supply circuit," in Proc. IEEE Int. Symp. on Industrial Electron., 2010, pp. 979-985. 